Article

\title{
Kinetically Deposited Copper Antimicrobial Surfaces
}

\author{
Victor Champagne ${ }^{1}$, Kristin Sundberg ${ }^{2}$ and Dennis Helfritch ${ }^{3, *}$ \\ 1 Army Research Laboratory, Aberdeen Proving Ground, MD 21005-5201, USA; \\ victor.k.champagne.civ@mail.mil \\ 2 Worcester Polytechnic Institute, Worcester, MA 01609, USA; kristinsundberg@wpi.edu \\ 3 Survice Engineering, Aberdeen, MD 21017, USA \\ * Correspondence: dennis.j.helfritch.ctr@mail.mil; Tel.: 443-890-7813
}

Received: 13 February 2019; Accepted: 11 April 2019; Published: 17 April 2019

check for updates

\begin{abstract}
Bacterial and viral contamination of contact surfaces increases the risk of infection. A great deal of work has been done on the capabilities of copper and its alloys to protect against a variety of microorganisms endangering public health, particularly in healthcare and food processing applications. This work has conclusively shown the effectiveness of copper for touch surface disinfection; however, the optimum microstructural characteristics of the copper surface have not been established. The sterilization effectiveness of three kinetically sprayed copper surfaces and two copper feedstocks were examined. The surfaces were inoculated with methicillin-resistant Staphylococcus aureus (MRSA) and influenza A virus. After a two-hour exposure to the surfaces, the surviving microorganisms were assayed, and the results contrasted. These tests showed substantial antimicrobial differences between the coatings generated by the spray techniques and those obtained by different feedstock powders. The significance of the copper spray application was demonstrated, and the application-dependent mechanism for antimicrobial effectiveness was explained.
\end{abstract}

Keywords: antimicrobial; surface; copper; powder; spray

\section{Introduction}

Microbial contamination of surfaces directly increases infections in hospitals and food processing facilities [1]. The microbial contamination of hospital surfaces, including patient rooms, nurse stations, and kitchens is well documented [2-5]. It is known that airborne influenza nuclei can infect environmental surfaces, leading to human infection with hand-to-surface contact [6-8]. In addition to the required cleaning practices, self-disinfecting surfaces would clearly inhibit the spread of infectious diseases.

Laboratory studies have demonstrated copper's ability to kill more than $99.9 \%$ of the following disease-causing bacteria within $2 \mathrm{~h}$ of contact time: Staphylococcus aureus, Enterobacter aerogenes, Escherichia coli O157:H7, Pseudomonas aeruginosa, vancomycin-resistant Enterococcus faecalis (VRE), and methicillin-resistant $S$. aureus (MRSA). Increasing the copper content of alloys improves their antimicrobial effectiveness [9]. Rapid disinfection prevents the generation of protective biofilms [10].

The interaction of copper ions with cellular membranes resulting in a flow of ions in the intracellular matrix is hypothesized to be the microbial-killing mechanism [11]. TEM images show cytoplasm leakage from S. aureus and E. coli cell membranes on copper surfaces. These data show copper ion presence in the membranes of the microbes and indicate that the primary killing mechanism is membrane destruction by copper ions [12].

Viruses, as well as bacteria, have been shown to be killed by contact with copper. The Center for Disease Control and Prevention describes influenza transmission mechanisms as the airborne spread of infectious droplets onto individuals or surfaces [13]. Influenza A is a major cause of infection and 
mortality of young children and the elderly [14]. Between 20 and 30 million people died in the influenza pandemic of 1918. During the 2012-2013 influenza season, the deaths attributed to pneumonia and influenza in the United States peaked at 9.9\%, and exceeded the epidemic threshold for 13 consecutive weeks [15].

The Copper Development Association lists more than 400 copper alloys that are registered with the U.S. EPA as antimicrobial [16], and all surfaces have a minimum copper content of $60 \%$. These registered materials can be utilized for the control and inactivation of microbes on frequently touched surfaces in hospitals [17].

\section{Materials and Methods}

Surfaces that make contact with people and foods should be composed of copper or copper alloys, which can be achieved with solid copper or through a copper surface coating. Copper coatings are favored over solid structural copper because of cost considerations. Several metal spray methods can be used for depositing a copper surfaces, and an optimum deposition method should be identified.

\subsection{Antibacterial Surface Coating}

Three metal spray techniques were evaluated regarding the antibacterial activity of the copper surfaces produced by each. The commercial metal spray techniques evaluated were cold spray (high speed, kinetically deposited solid-state powder particles), plasma spray, and wire arc spray (moderate speed, kinetically deposited molten particles). The copper powder used for the antibacterial tests was ACuPowder 500A (mean diameter $16.9 \mu \mathrm{m}$, ACuPowder, Union, NJ, USA) for cold spray. The plasma arc used Praxair Cu-159 (-31/+5 $\mu \mathrm{m}$, Praxair, Danbury, CT, USA), and the wire arc spray used copper wire as feedstock.

Approximately $0.3 \mathrm{~mm}$-thick coatings were sprayed onto stainless steel coupons. Table 1 gives the estimated particle impact conditions for the three processes, as well as the porosity and oxide ranges of the resulting deposits. Ranges for particle velocities and temperatures result from the range of particle diameters present in the powders. Porosity and oxide ranges are typical for the three spray methods.

Table 1. Particle impact and deposition characteristics.

\begin{tabular}{ccccc}
\hline Spray/Property & Temperature $^{\circ} \mathbf{C}$ & Velocity m/s & Porosity $\%$ & Oxides $\%$ \\
\hline Plasma Arc & $1500-2500$ & $100-400$ & $\sim 5$ & $\sim 2$ \\
\hline Wire Arc & $1500-2500$ & $50-100$ & $\sim 10$ & $\sim 15$ \\
\hline Cold Spray & $150-400$ & $500-1000$ & $<1$ & $<1$ \\
\hline
\end{tabular}

Figure 1 shows cross sections of the deposits generated by the three spray methods. Differences in microstructures can be expected on the basis of the large differences experienced by impacting particles for the three methods. These differences in microstructure suggest that a variance in microbial destruction may also occur. Particle melting can be seen for the high-temperature plasma and wire arc processes. Large voids can be seen in the wire arc process cross-section. 

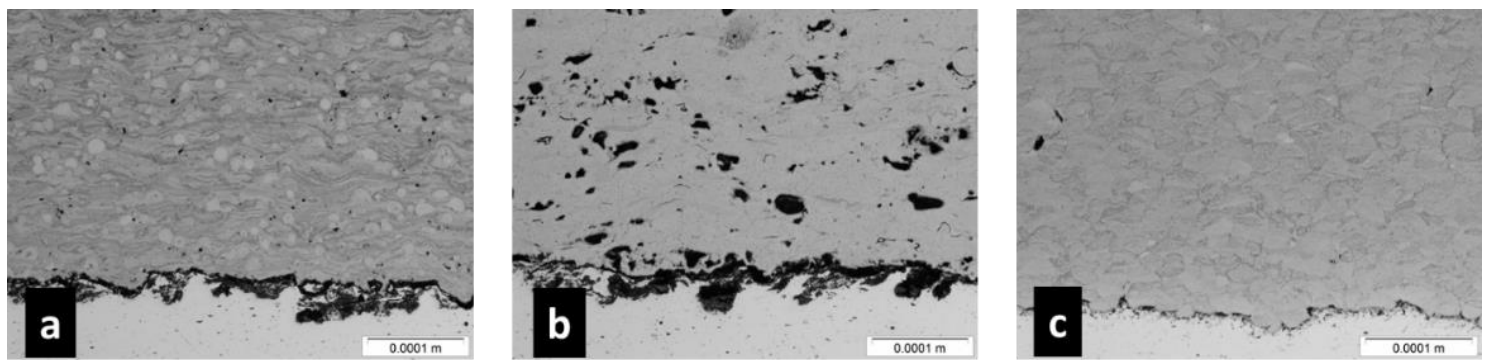

Figure 1. Deposited copper cross sections. Plasma (a), wire arc (b), cold spray (c). Stainless steel substrates can be seen at the bottom.

\subsection{Antiviral Surface Coating}

Antiviral effectiveness was compared for cold-sprayed conventional copper powder feedstock and nanometer-particle-diameter feedstock powder. The nano copper powder was composed of micron-sized agglomerates (mean $25 \mu \mathrm{m}$ ) of nanoscale particles. The conventional (Praxair Cu-159) and nano (Eltron Research and Development Inc., Boulder, CO, USA) copper powder feedstocks used for cold sprays are shown in Figure 2.
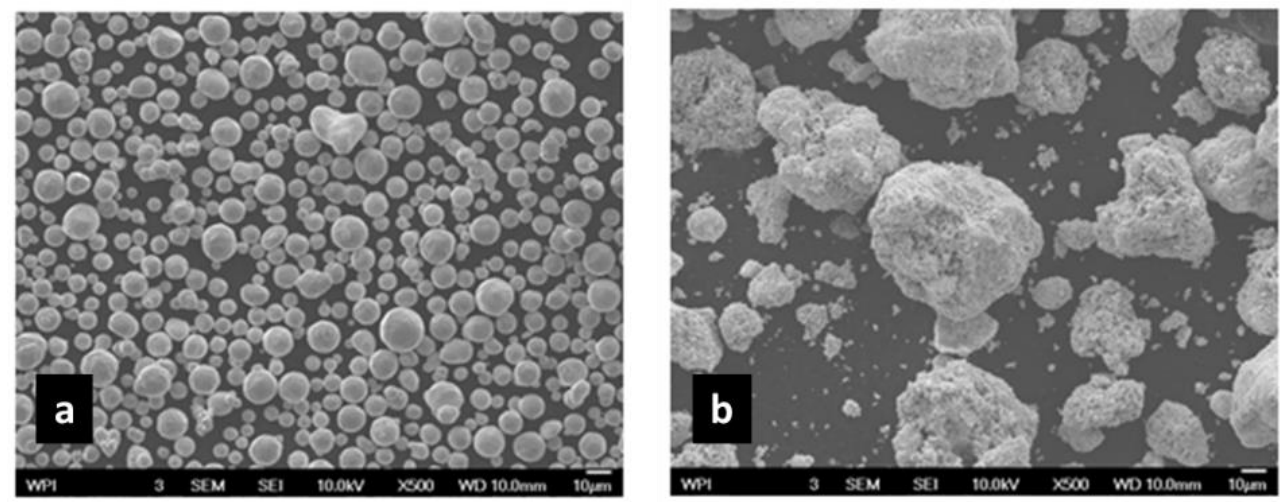

Figure 2. Conventional (a) and nanoscale (b) copper powders.

Cross sections of the deposits generated by cold spray for antiviral tests are shown in Figure 3. The deposits produced by both powders formed dense coatings. The nano-structured deposit was non-uniform, exhibiting microstructural differences. This may be representative of the non-uniform nature of the nano feedstock. The variance in microstructures implies a difference in biological activity between conventional and nano copper surfaces.
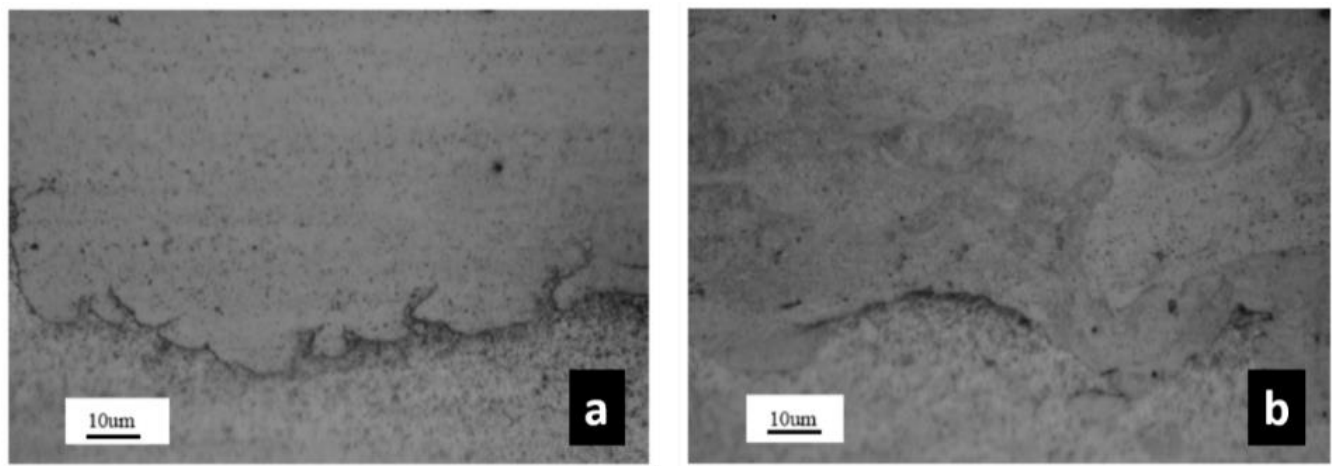

Figure 3. Cross-sectional views of the conventional powder (a) and the nanoscale powder (b) cold-sprayed deposits. 


\subsection{Microbiological Procedure}

The copper-coated coupons generated by the thermal spray devices in Section 2.1, as well as structural copper coupons, were inoculated with MRSA. The copper-coated coupons produced by cold spray for the conventional and nanoscale feedstock powders were inoculated with influenza A virus. Stainless-steel coupons were used as control substrates for both bacterial and viral tests. The inoculated coupons were then kept at room temperature for a given time period, after which survivors were re-suspended and cultured. The EPA Protocol, "Test Method for Efficacy of Copper Alloy Surfaces as a Sanitizer" was followed for the bacteria tests [18]. The EPA antimicrobial procedure was used with some changes for the influenza A tests as there is no EPA copper surface procedure for virus. The reduction of inoculated microbes was normalized by the results of the control exposure to a stainless-steel surface. The bacterial measurements were taken after $2 \mathrm{~h}$ of continuous exposure to the surfaces. The viral measurements were taken after several intermediate exposures up to $2 \mathrm{~h}$. The full details of the procedures are given in reference $[19,20]$.

\section{Results}

Figure 4 shows the percent of surviving S. aureus after $2 \mathrm{~h}$ of surface exposure. The results for cold-sprayed and structural copper were below the measurement thresholds and are thus reported as "less than". A three order of magnitude difference in disinfection efficiency between the plasma and wire arc methods and the cold spray method was observed. Differentiating between the results for the cold-sprayed surface and the structural copper surface was not possible, because of the measurement limit.

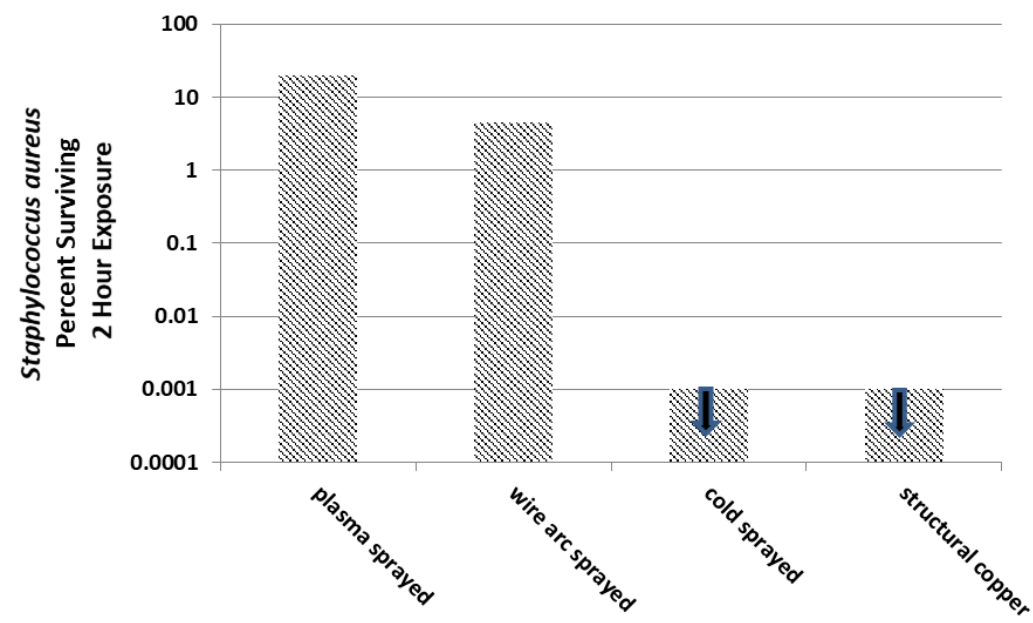

Figure 4. Percent methicillin-resistant Staphylococcus aureus (MRSA) surviving after a two-hour exposure to copper surfaces.

The results for viral killing are shown in Figure 5. As opposed to expectations, the result for the conventional copper cold-sprayed surface was very similar to that of the nano copper cold-sprayed surface, so it is not shown. The results obtained for the inactivation of influenza A on structural (wrought) copper (C1100) [21] were added to the graph for comparison. The difference in procedure between this current work and that of Noyce et al. is that this work utilized the TCID 50 Assay Protocol, while Noyce, et al. used a fluorescent dye that illuminated viral particles that were still infectious and counted virus particles recovered from the coupons under a microscope. Measurements were taken after 10, 30, 45, 60, 90, and 120 min exposures for the current work, while measurements were made after 60 and $360 \mathrm{~min}$ exposures for wrought copper. In both cases, the number of survivors on stainless-steel controls were orders of magnitude higher than on the copper surfaces. For clarity, the end points of the cold-sprayed copper data and the wrought copper were $0.13 \%$ at $120 \mathrm{~min}$ and $0.03 \%$ at $360 \mathrm{~min}$, respectively. 


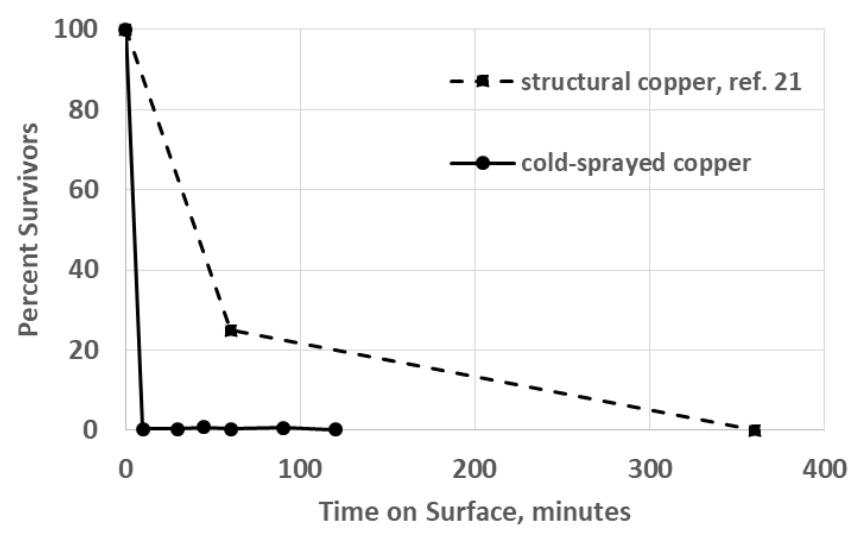

Figure 5. Percent of influenza A survivors as a function of exposure time to copper surfaces.

\section{Discussion}

The antimicrobial effectiveness obtained with sprayed copper deposition methods in comparison with that achieved with copper feedstocks needed an examination to determine the effects of powder feedstock and deposition process on the copper surface. In order to relate the nature of the deposit to its antimicrobial effectiveness, we needed to know the mechanism by which contact killing occurred.

Recent studies show that significant numbers of copper ions, $\mathrm{Cu}(\mathrm{II})$, are taken up by $E$. coli over a $90 \mathrm{~min}$ period, when an aqueous suspension (a standing drop) is used to apply cells to copper coupons. When cells are plated on copper using minimum liquid and a drying time of $5 \mathrm{~s}$, the buildup of copper ions by the cells was even greater, quickly reaching a high concentration. The copper ion level in the cells remained high throughout the disinfection phase, suggesting that the cells became overwhelmed by intracellular copper [22].

Copper ions added in solution to influenza A virus resulted in morphological abnormalities [23]. Studies show an increased sensitivity of covered viruses to copper ions as compared to uncovered viruses, indicating that the lipid membrane of the virus becomes overwhelmed by ionic copper, which is similar to the bacterial disinfection mechanism [24].

Thus, ionic copper is likely responsible for microbial killing; hence copper layers that maximize ionic copper diffusion to the surface are the best antimicrobials. Ionic diffusion in metals is enhanced by grain dislocations. Known as "pipe diffusion", significant ionic diffusion proceedsthrough these dislocations. The relationship between dislocation density and ionic diffusivity is given by [25]:

$$
D_{\text {eff }}=D_{0}\left[1+\pi a^{2} \rho_{\mathrm{d}}\left(\frac{D_{\mathrm{d}}}{D_{0}}-1\right)\right]
$$

where $D_{\text {eff }}$ is the effective ionic diffusivity; $D_{0}$ is the lattice diffusivity; $D_{\mathrm{d}}$ is the pipe diffusivity; $\rho_{\mathrm{d}}$ is the dislocation density; $a$ is the average dislocation radius.

In addition to dislocations, increased grain boundaries caused by impact breakup result in a similar augmentation of diffusion. The generation of ultra-fine-grained structures (including dislocations, dislocation cells, and twinning) caused by the high velocity impact of cold spray particles has been extensively documented [26-28]. Figure 6 shows the extreme plastic deformation of a copper particle after impact by cold spray [29]. A jet of plasticized material is typically ejected at the particle-substrate interface. 


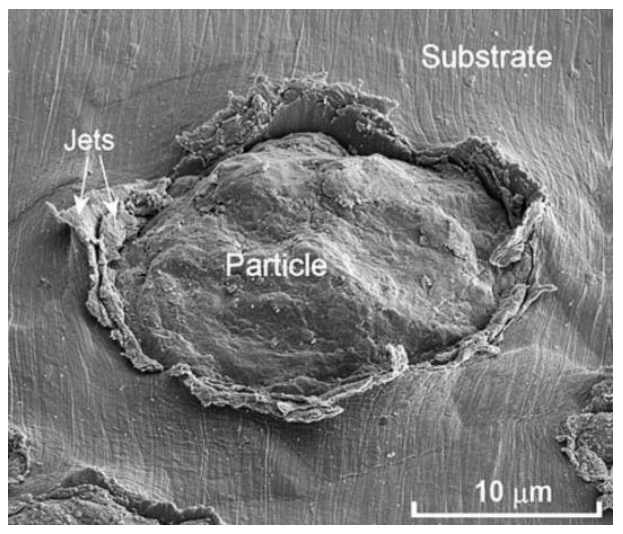

Figure 6. Example of cold-sprayed copper particle impact.

Gubicza et al. [30] measured the change in dislocation density by means of X-ray peak profile analysis of an initially annealed copper specimen, which was subsequently deformed by equal channel angular pressing. Their results are shown in Figure 7. The imposition of strain to the specimen, similar to what would happen to cold-sprayed particles, can increase the displacement density by a factor of six.

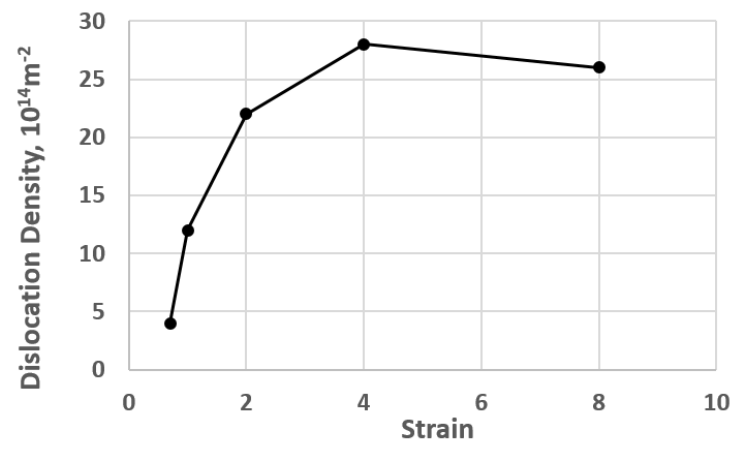

Figure 7. Copper dislocation density as a function of strain.

Luo and $\mathrm{Li}$ [31] showed how the dislocation density of cold-sprayed cBN/NiCrAl was decreased from its original cold-sprayed condition as the coating was annealed. Figure 8 shows a decrease of several orders of magnitude as the annealing temperature was increased from 750 to $900{ }^{\circ} \mathrm{C}$.

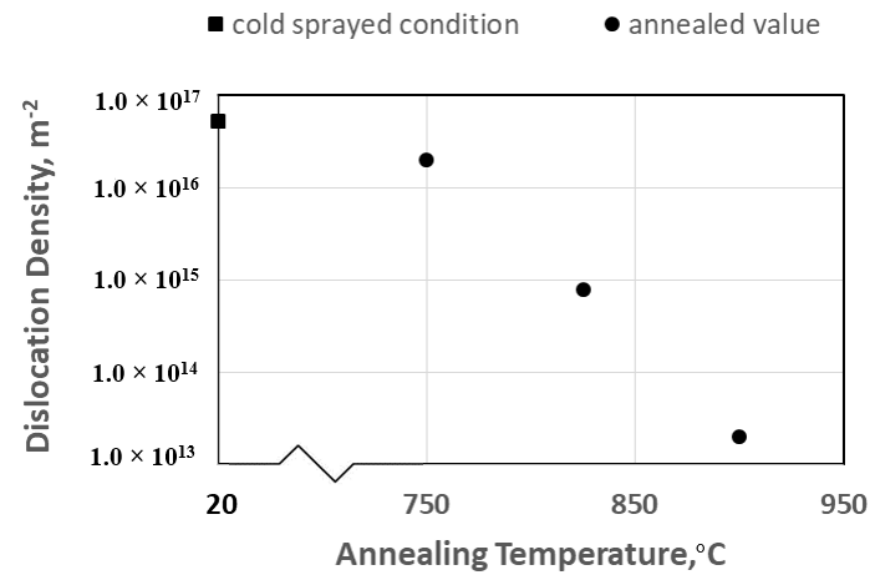

Figure 8. The displacement density of cold-sprayed $c B N / \mathrm{NiCrAl}$ as it is annealed. 
Thus, the process of cold-spraying copper can improve copper antibacterial activity through the generation of dislocations. The known effect of work hardening by cold spray is also a result of dislocation density growth.

The results showed that bacterial inactivation by cold-sprayed copper surfaces was more complete than viral inactivation. Hardier viral defenses may be one explanation. Roughness of the copper surface can contribute to improved contact-killing levels of influenza A virus by cold-sprayed copper, as opposed to wrought or structural copper, as shown in Figure 5. Bacteria such as MRSA range in size from 0.5 to $1.0 \mu \mathrm{m}$ in diameter, while viruses such as influenza A are on an 80-120 nm scale [32,33]. The size difference may have affected the ability of viruses to be fully affected by the extended surface area of cold-sprayed surfaces.

While not explicitly considered in this effort, the effects of copper surface oxidation on antimicrobial effectiveness has been studied by Hans et al. [34]. They found that the predominant oxide formed by atmospheric oxygen, $\mathrm{Cu}_{2} \mathrm{O}$, did not affect copper ion transport or antimicrobial effectiveness; however, $\mathrm{CuO}$, formed by wet oxidation, could decrease the effectiveness.

\section{Conclusions}

The significant anti-microbiological differences between copper coatings originating as powders or as wrought material and the differences between powder application techniques demonstrate the importance of the deposition structure. The cold spray method showed greater antimicrobial effectiveness relative to the other two thermal spray methods, due to the much greater impact velocity of the sprayed particles which resulted in high dislocation density and high ionic copper diffusivity.

Cold spray is a commercial process, used for a variety of applications requiring metal coatings. The cold spray process can thus apply effective anti-microbial copper coatings onto touch surfaces and will not damage heat-sensitive substrates. For example, a hospital tray and its entire metal support structure was coated with cold-sprayed pure copper at the Army Research Cold Spray Center.

Author Contributions: Conceptualization, V.C. and D.H.; Methodology, K.S. and D.H.; Formal Analysis, V.C.; Investigation, D.H. and K.S.; Writing-Original Draft Preparation, D.H.; Writing-Review and Editing, V.C.; Supervision, V.C.; Project Administration, V.C.

Funding: This research received no external funding.

Acknowledgments: The sanitizer testing conducted against MRSA and influenza A virus and reported in this paper was carried out under contract by ATS Labs at Eagan MN. The work was performed by Amy Jeske, Becky Lien, and Shanen Conway.

Conflicts of Interest: The authors declare no conflict of interest.

\section{References}

1. Page, K.; Wilson, M.; Parkin, I. Antimicrobial surfaces and their potential in reducing the role of the inanimate environment in the incidence of hospital-acquired infections. J. Mater. Chem. 2009, 19, 3819-3831. [CrossRef]

2. Aycicek, H.; Oguz, U.; Karci, K. Comparison of results of ATP bioluminescence and traditional hygiene swabbing methods for the determination of surface cleanliness at a hospital kitchen. Int. J. Hyg. Environ. Health 2006, 209, 203-206. [CrossRef] [PubMed]

3. Bernard, L.; Kereveur, A.; Durand, D.; Gonot, J.; Goldstein, F.; Mainardi, J.; Acar, J.; Carlet, J. Bacterial contamination of hospital physicians' stethoscopes. Infect. Control Hosp. Epidemiol. 1999, 20, 626-628. [CrossRef]

4. Rutala, W.; Katz, E.; Sherertz, R.; Sarubbi, F. Environmental-study of a methicillin-resistant Staphylococcus aureus epidemic in a burn unit. J. Clin. Microbiol. 1983, 18, 683-688. [PubMed]

5. White, L.; Dancer, S.; Robertson, C.A. Microbiological evaluation of hospital cleaning methods. Int. J. Environ. Health Res. 2007, 17, 285-295. [CrossRef]

6. Boone, S.; Gerba, C. Significance of fomites in the spread of respiratory and enteric viral disease. Appl. Environ. Microbiol. 2007, 73, 1687-1696. [CrossRef] 
7. Goldmann, D. Transmission of viral respiratory infections in the home. J. Pediatr. Infect. Dis. 2000, 19, S97-S102. [CrossRef]

8. Weber, T.; Stilianakis, N. Inactivation of influenza A viruses in the environment and modes of transmission: A critical review. J. Infect. 2008, 57, 361-373. [CrossRef]

9. Michels, H.; Wilks, S.; Noyce, J.; Keevil, C. Copper Alloys for Human Infectious Disease Control. In Proceedings of the Materials Science and Technology Conference, Pittsburgh, PA, USA, 25-28 September 2005.

10. Nie, Y.; Kalapos, C.; Nie, X.; Murphy, M.; Hussein, R.; Zhang, J. Superhydrophilicity and antibacterial property of a Cu-dotted oxide coating surface. Ann. Clin. Microbiol. Antimicrob. 2010, 9, 25. [CrossRef] [PubMed]

11. Grass, G.; Rensing, C.; Solioz, M. Metallic copper as an antimicrobial surface. Appl Environ. Microbiol. 2011, 77, 1141-1547. [CrossRef]

12. Lee, F.; Wang, D.; Chen, L.; Kung, C.; Wu, Y. Antibacterial nanostructured composite films for biomedical applications: Microstructural characteristics, biocompatibility, and antibacterial mechanisms. Biofouling 2013, 29, 295-305. [CrossRef]

13. CDC. Infection Control Measures for Preventing and Controlling Influenza Transmission in Long-Term Care Facilities. Available online: https://phpa.health.maryland.gov/OIDEOR/IMMUN/Shared\%20Documents/ LTCF_FluPrevention_Dec-2005.pdf (accessed on 15 April 2019).

14. Monto, A.; Ansaldi, F.; Aspinall, R.; McElhaney, J.; Montano, L. Influenza control in the 21st century: Optimizing protection of older adults. Vaccine 2009, 27, 5043-5053. [CrossRef]

15. CDC. Influenza Activity-United States, 2012-2013 Season and Composition of the 2013-14 Influenza Vaccine. Morb. Mortal. Wkly. Rep. 2013, 62, 473-479.

16. Copper Development Association. Properties of Wrought and Cast Copper Alloys. Available online: http://www.copper.org/resources/properties/db/basic-search.php (accessed on 15 April 2019).

17. Copper Development Association. The Copper Advantage: A Guide to Working with Copper and Copper Alloys. Available online: https://www.copper.org/publications/pub_list/pdf/a1360.pdf (accessed on 15 April 2019).

18. ALcontrol In-House Methodology. Test Method for Efficacy of Copper Alloy Surfaces as a Sanitizer. Available online: https:/www.antimicrobialcopper.org/sites/default/files/upload/media-library/files/pdfs/uk/ miscellaneous/bp51.3-copper-alloy-surfaces-as-a-sanitizer.pdf (accessed on 15 April 2019).

19. Champagne, V.; Helfritch, D. A demonstration of the antimicrobial effectiveness of various copper surfaces. J. Biol. Eng. 2013, 7. [CrossRef]

20. Sundberg, K.; Champagne, V.; McNally, B.; Helfritch, D.; Sisson, R. Effectiveness of nanomaterial copper cold spray surfaces on inactivation of influenza A virus. J. Biotechnol. Biomater. 2015, 5. [CrossRef]

21. Noyce, J.; Michels, H.; Keevill, C. Inactivation of influenza A virus on copper versus stainless steel surfaces. Appl. Environ. Microbiol. 2007, 73, 2748-2750. [CrossRef]

22. Santo, C.; Lam, E.; Elowsky, C.; Quaranta, D.; Domaille, D.; Chang, C.; Grass, G. Bacterial killing by dry metallic copper surfaces. Appl. Environ. Microbiol. 2011, 77, 794-802. [CrossRef]

23. Horie, M.; Ogawa, H.; Yoshida, Y.; Yamada, K.; Hara, A. Inactivation and morphological changes of avian influenza virus by copper ions. Arch. Virol. 2008, 153, 1467-1472. [CrossRef]

24. Sagripanti, J.L.; Routson, L.B.; Lytle, C.D. Virus inactivation by copper or iron ions alone and in the presence of peroxide. Appl. Environ. Microbiol. 1993, 59, 4374-4376.

25. Mehrer, H. Diffusion in Solids, Springer Series in Solid-State Sciences; Springer: Berlin, Germany, 2007; Volume 155, pp. 583-591.

26. Zhang, Y.; Brodusch, N.; Descartes, S.; Chromik, R.; Gauvin, R. Microstructure refinement of cold-sprayed copper investigated by electron channeling contrast imaging. Microsc. Microanal. 2014, 20, 1499-1506. [CrossRef]

27. Rokni, M.; Widener, C.; Champagne, V. Microstructural evolution of 6061 aluminum gas-atomized powder and high-pressure cold-sprayed deposition. J. Therm. Spray Technol. 2014, 23, 514-524. [CrossRef]

28. Borchers, C.; Gärtner, F.; Stoltenhoff, T.; Kreye, H. Microstructural bonding features of cold sprayed face centered cubic metals. J. Appl. Phys. 2004, 96, 4288-4292. [CrossRef]

29. King, P.; Zahiri, S.; Jahedi, M. Microstructural refinement within a cold-sprayed copper. Metall. Mater. Trans. A 2009, 40, 2115-2123. [CrossRef] 
30. Gubicza, J.; Balogh, L.; Hellmig, R.; Estrin, Y.; Ungar, T. Dislocation structure and crystallite size in severely deformed copper by X-ray peak profile analysis. Mater. Sci. Eng. A 2005, 400, 334-338. [CrossRef]

31. Luo, X.-T.; Li, C.-J. Thermal stability of microstructure and hardness of cold-sprayed cBN/NiCrAI nanocomposite coating. J. Therm. Spray Technol. 2012, 21, 578-585. [CrossRef]

32. Center for Disease Control Prevention, Electron Micrograph of Methicillin-Resistant Staphylococcus aureus (MRSA). Available online: http://faculty.ccbcmd.edu/courses/bio141/lecguide/unit1/shape/EM_MRSA_staph. html (accessed on 15 April 2019).

33. Verran, J.; Boyd, R. The relationship between substratum surface roughness and microbiological and organic soiling: A review. Biofouling 2000, 17, 59-71. [CrossRef]

34. Hans, M.; Erbe, A.; Mathews, S.; Chen, Y.; Solioz, M.; Mücklich, F. Role of copper oxides in contact killing of bacteria. Langmuir 2013, 29, 16160-16166. [CrossRef] [PubMed]

(C) 2019 by the authors. Licensee MDPI, Basel, Switzerland. This article is an open access article distributed under the terms and conditions of the Creative Commons Attribution (CC BY) license (http://creativecommons.org/licenses/by/4.0/). 